\title{
Quem tem medo da pedagogia? : contributos da teoria contemporânea da educação para resistir ao "regresso ao básico"
}

ELISABETE XAVIER GOMES Escola Superior de Educadores de Infância Maria Ulrich, Lisboa, Portugal

Este artigo parte dos ataques à pedagogia e assume a sua apologia. Refere modos infantis de pensar a (teoria da) educação em defesa de uma pedagogia pobre, de uma educação fraca e de uma infância estranha. Introduz um conjunto de abordagens teóricas que fazem a apologia de uma educação mais humana e menos humanista. Jacques Rancière (2002) e o modo como a aventura de Jacotot - o mestre ignorante - permite questionar um lugar-chave da educação: a explicação e a necessária desigualdade que caracteriza o acto educativo; Jorge Larrosa (2002), cujo conceito de experiência questiona a actividade como lugar sagrado da pedagogia moderna; e Gert Biesta (2006, 2010a), que ataca a necessidade da continuidade e do fim à vista dos processos educativos, propondo uma pedagogia da interrupção.

PALAVRAS-CHAVE

infância; alteridade; educação; pedagogia. 
WHO'S AFRAID OF PEDAGOGY? CONTRIBUTIONS OF CONTEMPORARY THEORY OF EDUCATION FOR RESISTING THE “RETURN TO BASICS"

\section{ABSTRACT}

This paper departs from a set of attacks on pedagogy and accepts its apology. It refers to childlike ways of thinking about education in defence of a poor pedagogy, a weak education and a strange infancy. It gathers a set of theoretical exercises that call for a more human and less humanistic education. Jacques Rancière's (2002) and the way of Jacotot's (the ignorant schoolmaster) adventure which question the key-place of education: explanation and the underlying inequality between student and teacher; Jorge Larrosa's (2002) concept of experience questions the activity, a sacred place of modern pedagogy; and Gert Biesta $(2006,2010 a)$ that tackles the taken for granted need to have foreseeable ends in education through the theory of a pedagogy of interruption.

KEYWORDS

childhood; otherness; education; pedagogy.

\section{¿QUIÉN TEME A LA PEDAGOGÍA? CONTRIBUCIONES DE LA TEORÍA CONTEMPORÁNEA DE LA EDUCACIÓN PARA RESISTIR LA “VUELTA A LO BÁSICO”}

\section{RESUMEN}

Este artículo toma como base de investigación los ataques que sufre la pedagogía, y asume su apología. Comenta los modos infantiles de pensar la (teoría de la) educación mediante la defensa de una pedagogía pobre, de una educación débil y de una infancia extraña. Se introduce un conjunto de enfoques teóricos que desarrolla la apología de una educación más humana y menos humanista: Rancière (2002) y la historia del maestro Jacotot -los maestros ignorantes- que permite discutir un punto clave de la educación: la explicación y la desigualdad que caracterizan el acto educativo; el concepto de experiencia de Jorge Larrosa (2002) y su cuestionamiento de la actividad como lugar sagrado de la pedagogía moderna; y Gert Biesta $(2006,2010 a)$ que ataca la necesidad de educar con un objetivo definido, proponiendo una pedagogía de la interrupción.

infancia; alteridad; educación; pedagogía. 


\section{INTRODUÇÃO}

Desde que me lembro, o reconhecimento e a assumpção do estado de crise nas sociedades ocidentais tem conduzido a uma mesma resposta nos terrenos da educação. A resposta tem sido a apologia dos modelos tradicionais de educação e às aprendizagens básicas e fundamentais, alicerçados na clara distinção hierárquica entre alunos e professores e em regimes disciplinares mais eficazes conducentes a resultados mais conformes e, logo, mais desejáveis - dizem. Hoje, em Portugal, como em muitos outros países, o movimento designado back to basics ganhou novo fôlego com as políticas de Nuno Crato, ${ }^{1}$ que, entre outras coisas, centrou o ensino nas disciplinas ditas fundamentais e fez renascer das cinzas os exames nacionais para o fim do $1^{\circ}$ ciclo do ensino básico, assim ensaiando modos de controlo e normalização do trabalho dos professores, das suas opções pedagógicas, bem como dos resultados conseguidos pelos alunos. Porém, há mais histórias dentro da história, e as panaceias normalmente são ilusórias - como tão bem nos mostra, por exemplo, o trabalho literário de Manuel António Pina:

- Esta história começa pelo fim. Mas não acaba no princípio. Acaba também no fim... embora noutro sítio do fim... [...]

Eram uma vez um príncipe e uma princesa que se casaram e foram felizes para sempre.

Mas "para sempre" é muito tempo e, com o passar dos anos, a felicidade do príncipe e da princesa começou a ter um sabor estranho e a tornar-se, como hei de dizer?, um pouco aborrecida.

- Que saudades eu tenho de quando era guardadora de patos!, dizia a princesa. - E eu que saudades tenho de quando era sapo, e esperava que tu chegasses e me beijasses para quebrar o feitiço!, dizia melancolicamente o príncipe.

(O príncipe e a princesa já estavam a ficar velhos e confundiam frequentemente as coisas, misturando com a sua história as histórias de outros príncipes e outras princesas de que tinham ouvido falar).

Um dia, passeando nos jardins do palácio, de mãos dadas, como sempre, concluíram que eram felizes há tanto tempo que já nem sabiam bem o que era a felicidade, e que, se ao menos se lembrassem de alguma coisa infeliz, talvez pudessem de novo aperceber-se de como eram felizes. [...]. (Pina, 2002, p. 19-20)

Este artigo começa pelo fim da história da pedagogia e acaba em outro fim, um fim em aberto. Porque "pressentimos o fim de um ciclo histórico iniciado em meados do séc. XIX, quando se inventou a modernidade escolar e pedagógica. Mas temos dificuldade em abrir caminho à contemporaneidade" (Nóvoa, 2005, p. 15). Tal como revela o excerto anterior de Manuel António Pina, é possível usar as referências históricas de modos dessacralizados; é possível ressignificar o

1 Ministro da Educação e da Ciência no XIX Governo de Portugal, em funções desde junho de 2011. 
estado "imperfeito" do qual as personagens evoluíram para sua felicidade eterna; não é impossível interpelar os fins sempre dados como desejáveis e certos e abrir espaço para (atribuir sentido a) acasos e desejos e outros fins.

Com esse modelo à vista, este artigo subscreve a tese de que é possível perturbar a matriz fundadora do pensamento sobre educação, aceitando sua história, seus acasos e o risco de pensamentos outros sobre a pedagogia. Fá-lo partilhando uma deambulação por teorias da educação que não prescrevem ações pedagógicas, mas suscitam abordagens e controvérsias que podem desencadear novas reações perante a pedagogia.

A pedagogia tem sido uma prática institucional, relacional, reflexiva e condicionada por vínculos a conceções e projeções idealistas e essencialistas de mundo e de ser humano. Desde a invenção da modernidade pedagógica, o ideário iluminista e humanista tem sido a face visível da justificação da existência da instituição escola, dos fins que serve e dos instrumentos e processos de que faz uso. $\mathrm{O}$ trabalho genealógico de Jorge do Ó (2003) tem promovido a compreensão da relação entre autoridade e autonomia como matriciais ao funcionamento da escola e da pedagogia - enquanto lugar e tecnologia de subjetivação e de normalização dos seres humanos. Percebida como elemento distintivo da educação escolar, oscilando entre versões tradicionais, versões modernas e outras, a pedagogia tem estado ao serviço de projetos políticos, sociais e culturais hegemónicos e que se regem, oficialmente, por versões de desenvolvimento social e humano. Eficaz demais para uns, perversa ou inútil para outros, a pedagogia é, hoje, como há um e há dois séculos, um campo de batalha. De um lado, as políticas de educação, de outro, as críticas - empírica, teórica, ideológica, sociológica, artística.

A globalização das economias, dos mercados e dos trabalhadores a par da transnacionalização das políticas da educação tem reforçado os argumentos para justificar a prestação de contas baseada mais nos resultados que nos processos de educação. Os rankings das escolas, a par de instrumentos de regulação nacional e internacional dos resultados da escolarização, promovem a entrada da lógica mercantil nos processos de educação. Pretende-se assim que a educação e o trabalho das escolas e dos professores sejam mais mensuráveis e comparáveis e que os vectores de distinção e diferenciação mecanizem-se e vejam sua eficácia burocraticamente controlada e certificada.

Em contrapartida, vêm os fantasmas distópicos associados à eficácia da pedagogia. Fundada em uma recolha empírica de dados diversificados sobre a sociedade francesa dos anos 1980, Jacky Beillerot (1985) desenvolveu a tese da disseminação da (nefasta) ação pedagógica por toda a sociedade. As evidências encontradas pelo autor são transversais aos domínios de existência humana - escolas, fábricas, lojas, famílias, política, marketing. Questiona a relação com o saber e a modelação de comportamentos, com cenários convergentes com as distopias sociais de Orwell, por exemplo, quando se refere à "era do grande pedagogo" e ao controle social por meio da pedagogia. Sua conclusão é de que se vivia na sociedade pedagógica uma espécie de apogeu dissimuladamente totalitário das sociedades industriais que remete para um prenúncio distópico sobre a contemporaneidade. 
Essa leitura de mundo parece persistir, como se pode perceber pela abordagem de Bernstein (2001), que, no seu último texto, quase duas décadas depois, refere-se à nossa como uma sociedade totalmente pedagogizada ${ }^{2}$ e propõe o enaltecimento dos conhecimentos e a secundarização da pedagogia. Bernstein analisou a emergência de evidências dessa disseminação da pedagogia pelos vários domínios sociais, iluminando casos-chave no Reino Unido, como a reconfiguração das famílias em espaços para o exercício de competências paternais, a emergência da figura do conselheiro de mapeamento de carreira dos adolescentes ou a persistente aprendizagem ao longo da vida dos adultos. A base da sociedade totalmente pedagogizada é a relação pedagógica, entendida como a "que normaliza as intimidades do desejo, das aspirações públicas, da conduta e das suas práticas através da sua modelação pelas macroestruturas" (idem, p. 12).

De fora dos estudos sobre educação e prática pedagógica, relembro, por exemplo, Lefebvre e seu menosprezo pela educação enquanto elemento da vida em sociedade, quando afirma que "o educativo atrai mas não seduz nada e muito menos encanta. A pedagogia implica práticas localizadas e não uma centralidade social" (Chão, 2007, p. 80). Mais recentemente, Virno (2012, p. 34) define de forma acurada o problema que me interessa abordar:

de Rousseau às comunas antiautoritárias de 1968, a atenção dos reformadores e revolucionários para com o ser humano principiante resultou em pedagogia. Isto é, na tentativa de colocar a formação da criança de acordo com o ideal de uma sociedade mais justa.

Nesse sentido, assumo o repto de pensar a possível libertação da ideia de que a educação de cada ser humano está ao serviço de um projeto social, cultural e político. Neste artigo, começo por apresentar um modo outro de pensar a (teoria da) educação; reúno a apologia de Fendler (2012) por uma teoria da educação vibrante e menos moderna, com os princípios de uma educação fraca (Biesta, 2010b) e uma metodologia pobre (Masschelein, 2008). Considero que esses princípios teóricos abrem caminho para - e caminham sobre - o repensar a infância e as crianças (símbolos principais dos sujeitos-alvo da pedagogia) em sua radical alteridade, de que nos falam Larrosa (2000) e Smeyers e Wringe (2003).

$\mathrm{Na}$ segunda parte deste artigo, apresento um conjunto de propostas teóricas consistentes com o questionamento das ideias e ideais humanistas relativos ao ser humano e à sua educação, defendendo que é possível equacionar a humanidade dos seres humanos e conceber processos de educação sem definir abstractamente e totalmente as características últimas dos sujeitos educados ao serviço de qualquer idealização de sociedade. Aqui serão reunidas as minhas leituras de três livros (e alguns textos adjacentes) que trazem novos fins à pedagogia. Jacques Rancière

2 De acordo com o autor, a nossa é a segunda sociedade totalmente pedagogizada. $\mathrm{Na}$ Idade Média, a Igreja católica terá disseminado uma base pedagógica de controlo dos seres humanos em virtude de uma vida futura no paraíso. Já a nossa tem como actor central o Estado capitalista e neoliberal. 
(2002) e a aventura de Jacotot em O mestre ignorante, publicado originalmente em 1987 - permite questionar um lugar-chave da educação forte: a explicação e a necessária desigualdade que caracteriza o acto educativo. A Pedagogia profana, de Jorge Larrosa (2000), permite repensar a infância e a educação como relação com o novo, reactivando o conceito central de experiência. Gert Biesta, no livro Beyond learning (2006), fundamenta a impossibilidade de manter a educação vinculada ao projecto iluminista e ao ideário do humanismo, propondo uma pedagogia da interrup̧̧ão.

É por isto que escrevo este artigo: não por vontade de desenhar uma proposta pedagógica unificada baseada em percursos teóricos diferenciados, mas pela validade do exercício de estranhamento perante a infância e sua educação como exercício de resistência à imunização que cada vez mais e mais a escola promove e a que se refere o balanço cru de Skliar (2003, p. 240):

Deixamo-nos de comover na escola.

A vida foi embora da escola, e a única solução que achamos para fazê-la retornar foi a de retratá-la no currículo. Fizemos séries e ciclos com a vida. Mas não vivemos a vida na escola. Nem vivemos a nossa vida, nem vivemos a vida deles, nem vivemos a vida dos outros. Não vivemos na escola.

Reformamos a vida, mas não vivemos a vida na escola.

Explicamos a vida, mas não vivemos a vida na escola.

Fazemos o simulacro de compreender a vida na escola, mas não a celebramos.

\section{PARA NÃO TER MEDO DA PEDAGOGIA FORTE: EDUCAÇÃO FRACA, METODOLOGIA POBRE, INFÂNCIA ESTRANHA}

A teoria e a investigação são instrumentos para melhor conhecer o desconhecido; contudo, elas são, hoje, também, um vigoroso incitamento a estranbar o familiar. Esse é um dos domínios da teoria da educação que me têm interessado e desconcertado. Encontrar argumentos que nos façam estranhar os elementos constituintes do cenário educativo tradicional incita a repensar, reconfigurar e mesmo imaginar o que pode ser a educação.

Lynn Fendler (2012, p. 321) interpreta e organiza os modos como a teoria tem estado presente na investigação sobre e na educação. Um de seus argumentos é de que grande parte da teoria da educação é (ainda) moderna, no sentido de que, para garantir sua validade, deve ser generalizável, deve ter um poder preditivo e uma coerência racional. Perante essa e outras constatações, a autora pergunta-se quais poderiam ser os papéis da teoria da educação, hoje, perante uma experiência tão vasta de educar e escolarizar e perante um cenário epistemológico que já não é moderno. Sua resposta desenvolve-se em torno de três possibilidades: a teoria da educação pode ser hiperbólica, generativa e vibrante. Hiperbólica no sentido de que a teoria da educação pode empurrar o pensamento para fora dos limites, suscitando a emergência de alternativas aos mecanismos reprodutivos que têm invadido os processos de educação e escolarização. A emergência de alternativas constitui-se como 
um gesto generativo por desencadear outros gestos, e não apenas sua reprodução; e é assim que se introduz alguma vibração: "a vibração ressignifica temas de pedagogia de modo que o ensino deixa de ser perspectivado como um processo de fornecimento unidirecional de informação oficial, mas antes como um processo de relações dinâmicas, democráticas e experienciais" (idem, p. 326, tradução minha).

É interessante destacar que o trabalho de Fendler surge nos Estados Unidos da América, país onde o movimento back to basics, que faz um uso reforçado dos fundamentos teóricos modernos, tem recorrentemente assaltado as reformas educativas. De facto, como clarifica Fernandes (2000), é na literatura norte-americana que se sintetiza a fórmula dos " $3 \mathrm{rs}$ " - reading, writing, and arithmetics (ler, escrever e contar). Essa fórmula curricular concretiza-se em um "ensino transmissivo e centrado no professor, que promove o trabalho individual como forma de verificar se os conhecimentos foram adquiridos e não como meio de estimular o desejo de aceder a novos conhecimentos" (idem, p. 94). As dimensões curriculares e pedagógicas desse movimento assentam em uma mitificação do passado que negligencia aspectos nefastos dos sistemas educativos tradicionais (de que o insucesso e o abandono escolares ou a reprodução das desigualdades são exemplos) para enaltecer o tempo em que, supostamente, os professores ensinavam e os alunos aprendiam.

Hoje, em Portugal, nós, professores e educadores (e mães), estamos perante um novo ciclo do regresso ao básico, por via de um conjunto amplo e heteróclito de medidas políticas. Destaco aqui apenas: o aumento do número de alunos por turma e por escolas e a redução das aprendizagens ao que é objectivamente mensurável. A preferência por um ensino mais centrado no professor legitima o incremento do número de alunos por sala e por escola, na medida em que as actividades dos alunos deverão ser rigorosamente antecipadas e controladas pelos professores mais eficazes, assim como as suas diferenças e especificidades nas diferentes fases de desenvolvimento.

Em 2010 deu-se início ao reordenamento da rede de escolas públicas, originando os chamados mega-agrupamentos, nos quais um conjunto de escolas de todos os níveis de ensino não superior passa a ter um projecto educativo e uma estrutura de direcção única - hoje são cerca de vinte os mega-agrupamentos que têm mais de três mil alunos, desde a educação pré-escolar até ao fim do ensino secundário. No ano lectivo 2012/2013 houve um alargamento do número de alunos por turma - no $1^{\circ}$ ciclo do ensino básico, o número máximo passou de 25 para 26 alunos por turma; no $2^{\circ}$ e $3^{\circ}$ ciclos do ensino básico, passou de 26 para 30 alunos por turma; e para o ensino secundário são ditados os números mínimos de funcionamento de cada turma dependendo das áreas de especialização, não sendo sempre claro o número máximo de alunos (veja-se o despacho n. 5.048-B/2013).

Associando-se mais claramente às tendências do "back to basics/regresso ao básico”, a revisão em curso dos programas do ensino básico assenta na retórica político-ideológica de reforço do que se consideram saberes fundamentais - que se equivalem aos que são mensuráveis e sublinham as disciplinas de português e matemática. Para além dos programas, os professores do ensino básico têm agora também como elemento de trabalho e planeamento as "Metas Curriculares" para as várias disciplinas fundamentais, acompanhadas de documentos de apoio ao 
professor que oferecem estratégias de ensino prontas a usar. Uma leitura desses documentos permite evidenciar uma concepção atomizadora da aprendizagem e seu carácter marcadamente comportamentalista. ${ }^{3} \mathrm{Na}$ sequência da definição estrita de itens de aprendizagem, foram reintroduzidos em Portugal os exames nacionais de português e matemática no fim do $4^{\circ}$ ano de escolaridade, precedidos de provas nacionais intercalares no final do $2^{\circ}$ ano de escolaridade. $\mathrm{O}$ regresso ao básico assenta na crença de que a situação educativa, se for devidamente controlada por meio do uso de técnicas pedagógico-didácticas fortes e eficazes, permite alcançar os resultados desejados: produzir um certo modo de ser humano. É contra essa acepção do agir pedagógico que escrevo este artigo na senda de tantos outros autores e movimentos de reacção às crises civilizacionais.

"O humanismo já não é suficiente humano", afirmou Levinas no pós-guerra, desencadeando um debate sobre a negação da possibilidade e da desejabilidade de abordagens humanistas, essencialistas e racionalistas ao ser humano. Retomemos a radical dúvida de Levinas (1988, p. 26): "Mas como é que o Mesmo, produzindo-se como egoísmo, pode entrar em relação com o Outro sem desde logo o privar da sua alteridade?". Com mesmo, pretende-se nomear o conhecido, a identidade do ser que se diz e que é referido como modelo de referência; com outro, pretende-se referir aquele que é estranho, que está fora do modelo de referência. O outro tem como característica essencial não ser o mesmo, ou seja, suas características específicas são desconhecidas, logo o outro é-o formalmente, e não devido ao seu conteúdo. Quando, no contexto deste texto, é referida a alteridade, pretende-se referir à relação entre o outro (criança e infância) e o mesmo (adulto e adultez), propondo uma relação que assuma a estranheza, o desconhecido, desse outro com que nos relacionamos, sem querer reduzir o outro ao mesmo; essa é uma relação de transcendência que:

designa uma relação com uma realidade infinitamente distinta da minha, sem que esta distância destrua por isso esta relação e sem que esta relação destrua essa distância, como aconteceria para as relações dentro do Mesmo; sem que esta relação se torne uma implantação no Outro. (idem, p. 29)

Em sua crítica ao humanismo, Lyotard (1989) afirma a relevância de manter a alteridade como elemento da sobrevivência do humano, referindo-se nomeadamente ao inumano. $\mathrm{O}$ autor remete para uma segunda abordagem à alteridade associando-a ao indeterminismo da vida humana que fundamenta, nomeadamente, a educação. O diálogo entre o indeterminismo humano e a crítica ao humanismo

3 Vejam-se os seguintes exemplos paradigmáticos: "Utilizar o termo 'ponto' para identificar a posição de um objeto de dimensões desprezáveis e efetuar e reconhecer representações de pontos alinhados e não alinhados" (Metas Curriculares da Matemática, $1^{\mathrm{o}}$ ano. Disponível em: <http://dge.mec.pt/metascurriculares/>); "Ler um texto com articulação e entoação razoavelmente corretas e uma velocidade de leitura de, no mínimo, 55 palavras por minuto" (Metas Curriculares de Português, $1^{\circ}$ ano. Disponível em: $<$ http://dge.mec.pt/metascurriculares/>). Acesso em: 11 dez. 2013. 
permite compreender a introdução da ideia dupla do inumano: "existiriam assim dois tipos de inumano. É indispensável mantê-los dissociados. A inumanidade do sistema em curso de consolidação, sob o nome de desenvolvimento (entre outros), não deve ser confundida com aquela, infinitamente secreta, de que a alma é refém" (idem, p. 10).

Biesta $(2006,2010$ a) procura respostas educativas a esses temas, que começam por ser filosóficos, e escreve sobre a fraquez $a^{4}$ da educação. A fraqueza da educação é também sua força, nova e tolerável: ela reside na assumpção de que a educação não produz seres humanos e que a pedagogia não é uma tecnologia de fabricação de seres com características antecipadamente definidas. Biesta (2006) interroga a idealização humanista que ainda subjaz aos processos e retóricas de educação e escolarização e considera que a humanidade de cada indivíduo não é um dado garantido à partida, tal como a singularidade não é uma consequência directa da existência individual. Assim, propõe o deslocamento da questão sobre o ser humano: em vez de procurar as características e elementos que definem a essência da humanidade, analise-se a existência procurando perceber se, quando e como a humanidade existe. Porque, defende, ser um sujeito humano não é um estado que se atinja na vida (seja pela idade, maturidade, condições de vida etc.), mas é antes um acontecimento, algo que ocorre na relação responsável com os outros, em um mundo comum e plural.É essa a convicção que deverá estar na base de uma educação fraca.

Jan Masschelein (2008) desenvolve uma perspectiva convergente ao fazer a apologia de metodologias pobres para conduzir pesquisa educacional crítica: a que não oferece lucros, nem certezas, nem lições, mas sim tempo, experiência e atenção. De muitos modos essas abordagens teóricas são consistentes com a própria prática educativa, se entendida em uma perspectiva existencial, e não essencialista. Como tal, essa metodologia é também uma pedagogia.

A pedagogia pobre nos convida a sair para o mundo, a nos expormos; em outras palavras, a nos colocarmos numa "posição" fraca, desconfortável, e oferece meios e apoio para que façamos isso. [...] não coloca sob vigilância, ela não controla, ela não está tomando conta de um reino (o reino da ciência, da racionalidade, da moralidade, da humanidade, etc.), ela não impõe condições para a entrada... Caminhar e copiar são os nomes para todas as práticas educativas que permitem a experiência e a exposição. Elas implicam abdicar do conforto de uma posição (de uma orientação, uma boa intenção, uma consciência, uma explicação ou uma história). (idem, p. 43-44)

Perspectivam-se assim modos de equacionar a metodologia e a epistemologia que se afastam das lógicas modernas e positivistas, procurando abordagens à ciência e à educação que sejam de uma natureza não determinada nem determinista. Nos anos subsequentes às revoltas académicas de 1968, René Schérer (2009) escreveu uma obra de interpelação a um cânone do pensamento pedagógico moderno:

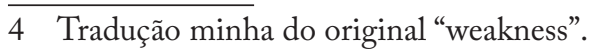


Émile péverti. Já nos anos 2000, o autor retoma a crítica a Rousseau e à educação negativa constatando que "a infância no Émile está sempre sob o jugo do preceptor" (Schérer; Gil; Brito, 2012, p. 73). O trabalho de Schérer permite questionar o tema da menoridade e da maioridade da infância, apontando para sua coexistência na paradoxal defesa de uma menoridade maioritária - resistindo aos consensos que se têm gerado ora em torno da defesa da menoridade ou da maioridade e ao papel da educação como superação da menoridade (infantil) e percurso para a maioridade (adulta). Com menoridade maioritária, Schérer fala da convocação para a cena pública da menoridade da infância que sintetiza em: "impulsão, inovação, abertura aos possíveis, disponibilidade, despreocupação" (idem, p. 69). Como modos de resistência à superação da menoridade que os sistemas educativos têm vindo a procurar, o autor refere-se ao processo inacabável de devir-criança, pois ser criança não é apenas uma idade cronológica, é um existir no mundo.

Essa perspectiva pode ser aprofundada com os trabalhos de Jorge Larrosa. Em uma colecção de textos reunida na obra Pedagogía profana, Larrosa (2000) faz uso de um conjunto de imagens e referências que afirmam a alteridade da infância e o modo como esta subjaz à educação. Propõe um entendimento das crianças como figuras do porvir, acentuando a imprevisibilidade que as crianças e o conceito de infância encerram.

A infância como alteridade não se limita ao que $j a ́$ fomos capazes de submeter à lógica cada vez mais refinada dos nossos procedimentos e das nossas instituições, mas também não pode ser confundida com o que ainda não fomos capazes de subjugar. O que ainda nos resiste justifica o nosso poder e de todos os modos o questiona. Os que sabem continuam a investigar; os políticos continuam a fazer planos e projetos, os grandes armazéns continuam a inovar seus catálogos, os produtores de espetáculos continuam a fabricação de novos produtos, os profissionais continuam a melhorar as suas práticas e os lugares em que as crianças são acolhidas, aumentando e adaptando-se cada vez mais aos seus utilizadores. Todos trabalham para reduzir o que ainda há de desconhecido nas crianças e para submeter o que neles ainda há de selvagem. (idem, p. 166-167, tradução minha)

Algumas ideias-chave do pensamento do autor sobre a existência humana são aqui sintetizadas na imagem da criança:

- a irredutibilidade das crianças (enquanto novos seres humanos) a qualquer tipo de antecipação, seja humanista ou consumista, educativo ou nostálgica, economicista ou político;

- a incessante demanda das instituições e dos poderes instituídos para se aperfeiçoar na arte de captar e reduzir a criança a um modelo antecipado e universal (no sentido em que é válido para todas as crianças) ao serviço de um projecto social;

- a desafiadora resistência das crianças à sua captura institucional e racional, como símbolo do misterioso, do não dito e do não previsto. 
O que aqui está em questão é o confronto entre certa adultez instituída pelos poderes vigentes e uma infância potencialmente instituidora de novas ordens, novos processos e novos modos de vida: uma infância estranha ao futuro que os adultos the querem oferecer. Essas dificuldades da relação do ser adulto e normalizado com a alteridade e o mistério encerrados pela infância emergem, no âmbito da filosofia da educação e designadamente a partir de Arendt (2000,2001), como a justificação cabal do acto educativo: é porque esse confronto existe que existe educação, é porque há o novo (em cada criança) e o velho (em cada adulto e em cada instituição).

É desse modo que se poderá entender a infância como o estranho inumano, como aquilo que nos humanos não pode ser conformado totalmente às regras $\mathrm{e}$ antecipações racionais. É ainda marcante a ligação estabelecida com o tema "educação" como um dos elementos desse sistema normalizado para o qual a sensibilidade a essa abordagem à infância surge como uma alternativa poderosa, no sentido de que introduz um movimento em contramão por requerer abertura de percepção e espaço ao acontecimento $^{5}$ que são a criança e a infância e às dimensões que nelas não podem ser classificadas, medidas ou categorizadas, tal como uma educação forte e de base essencialista promove. Smeyers e Wringe (2003, p. 324-325) defendem que a infância nos apresenta a um tempo em que o futuro não é uma consequência do passado e no qual o que vem a este mundo não pode ser inferido a partir do que já existe: a infância não representa o que é possível, representa, sim, o que é impossível.

\section{POR UMA PEDAGOGIA OUTRA: MESTRE IGNORANTE, EXPERIÊNCIA PASSIVA, PEDAGOGIA DA INTERRUPÇÃO}

o que acontecerá se tentarmos superar os fundamentos humanistas da educação moderna [...] se tratarmos a questão do que significa ser humano como uma questão radicalmente aberta, uma questão que só pode ser respondida pela implicação em processos de educação e não como um pergunta que precisa ser respondida antes de nos podermos envolver em processos de educação. (Biesta, 2006, p. 4-5, tradução minha)

O objectivo desta secção é convocar trabalhos contemporâneos de teoria da educação que permitem religar a educação ao humano, colocando no centro a alteridade da infância e o carácter existencial da educação. O objectivo não é propor um sistema pedagógico total e coerente, é, tão só, iluminar possíveis instrumentos teóricos que provoquem a assumpção do risco das actividades de educação - que sejam excessivos ou generativos ou vibrantes. Nesse sentido, dou a ler minha interpretação, minha selecção e minha cópia (copiar é, afinal, uma das estratégias da pedagogia pobre atrás referida) de três textos que fizeram vibrar meu pensamento

5 Acontecimento remete para o que é antes de lhe ser atribuído um significado particular e assim delimitado, antes de ser rotulado e conceptualizado. 
sobre educação e minha prática como professora de professores. Escolhi-os para meu argumento de que é possível pensar o pensamento da diferença em pedagogia; o primeiro texto (Rancière, 2002) questiona a explicação como instrumento central da educação forte e da pedagogia total; o segundo (Larrosa, 2002) estabelece uma ligação paradoxal entre experiência e passividade, pondo assim em questão a actividade como princípio-chave das pedagogias novas; e o terceiro (Biesta, 2006, 2010a) questiona as determinações apriorísticas da educação e propõe a interrupção como marca de um novo agir pedagógico.

\section{IGUALDADE, DESIGUALDADE E A CRÍTICA À RAZÃO EXPLICADORA: O MESTRE IGNORANTE A PARTIR DE JACQUES RANCIÈRE}

Em meados dos anos 1980, o filósofo francês Jacques Rancière (2002) publicou um livro que recupera a história de Joseph Jacotot (um pedagogo francês do século XVIII-XIX) e analisa seus princípios para a acção educadora. No início do século XIX, Jacotot vê-se em uma situação de tal modo impossível que força um novo olhar perante a gramática educadora e escolarizadora que lhe foi contemporânea. Tendo sido um revolucionário em 1789, viu-se exilado em Lovaina aquando da restauração da monarquia francesa, onde trabalhou como leitor de francês na universidade. Quando iniciou seus trabalhos, Jacotot verificou que a turma que o aguardava falava apenas o neerlandês, língua que, por sua vez, desconhecia em absoluto. Esse professor ficou, assim, impossibilitado de fazer uso daquilo que permanece como uma das estratégias mais centrais da escolarização: a transmissão oral do conhecimento do professor para os alunos - como transmitir se não existe uma língua comum? A resposta encontrada por Jacotot foi substituir essa estratégia que assenta na língua como elemento comum por outro elemento comum. $\mathrm{O}$ encontrado foi uma edição bilíngue (em francês e neerlandês) de um clássico da Antiguidade grega - o Telémaco. $\mathrm{O}$ facto de ter sido bem-sucedido e de os alunos se terem ensinado a escrever e a ler francês (idem, p. 20-22) suscitou um conjunto de reflexões e de propostas educativas, e Jacotot atreveu-se a repetir a abordagem com outras matérias e assuntos.

Para além de ser uma saga surpreendente e deliciosa, Rancière apresenta uma sistematização muito enriquecedora, iluminando princípios que subjazem a essa aventura intelectual. De entre as acepções de Rancière, apresentam-se a seguir dois vectores de análise fundamentais para abrir espaço a outra pedagogia: o lugar paradoxal e dissonante que atribui à igualdade e à sua relação com a desigualdade nas propostas de Jacotot; a frutífera crítica à razão explicadora que encerra a figura do mestre ignorante.

No que se refere à problematização da igualdade, é preciso começar por afirmar que ela é entendida como salutar, não tanto em suas manifestações efectivas, mas experimentais, isto é, percebendo os impactos que acreditar na igualdade tem sobre as práticas relacionais, nomeadamente as práticas educadoras. Vejamos,Jacotot, enquanto professor do dealbar de novos e simbólicos sistemas educativos públicos, começa por verificar sagazmente o que torna possível a escola como instrumento de promoção da ordem social pós-revolucionária: considera que a escola ergue-se sobre a evidência das várias desigualdades sociais, nomeadamente a desigualdade 
entre os que sabem e os que não sabem. Constatada a desigualdade, o papel central da escola nas sociedades seria de procurar corrigir essas desigualdades pela instrução, assumindo como objectivo da educação a igualdade dos sujeitos, cidadãos do progresso e da razão (ideário do regime em que Jacotot desenvolveu a primeira parte de sua vida profissional). A distância crítica a que Jacotot teve acesso com seu exílio e seu desconforto perante a impossibilidade da transmissão do conhecimento permitiu mudar a perspectiva, quebrar os círculos do entendimento convencional e evidenciar outras dimensões. Considerando que

A pedagogia tradicional da transmissão neutra do saber, tanto quanto as pedagogias modernistas do saber adaptado ao estado da sociedade mantêm-se de um mesmo lado, em relação à alternativa colocada por Jacotot. Todas as duas tomam a igualdade como objetivo, isto é, elas tomam a desigualdade como ponto de partida.

As duas estão, sobretudo, presas no círculo da sociedade pedagogizada. Elas atribuem à Escola o poder fantasmático de realizar a igualdade social ou, ao menos, de reduzir a "fratura social". (idem, p. 12)

Jacotot acusa a escola de reproduzir as desigualdades, em vez de as corrigir, porque estas a sustentam e a justificam - o que ocorre pela perpetuação de modelos pedagógicos que assentam na explicação das coisas que é dada pelo que sabe ao que ignora e que assim torna quem ignora dependente de quem sabe, mantendo-se em desigualdade e promovendo novas desigualdades pelo poder que as explicações conferem ao novo explicado perante um novo ignorante.

Voltando à aventura de Jacotot, constata-se o modo como todos os alunos aprenderam o francês pelo contacto directo e sem mediação com o livro escrito nas duas línguas, página a página. Uma de suas justificações encontradas é relativa ao modo como esses estudantes aprenderam, porque também eles tinham o livro, e não apenas o intermediário. O livro como símbolo material do conhecimento, que, nessa história, é igual para todos: professor e estudantes, todos em iguais circunstâncias, ninguém domina todo o livro, nem a posse ou o acesso são exclusivos de uma das partes. É na compreensão e análise desse acontecimento que emerge a declaração da igualdade. Mas essa não é uma igualdade qualquer nem total: é a igualdade das inteligências de todos, alunos e professores, alunos entre si, ignorantes e sábios. Rancière estende a igualdade da inteligência a todos os humanos não como um direito, mas como um elemento central e definidor de ser humano e potenciadora de uma relação outra entre eles:

A igualdade, ensinava Jacotot, não é nem formal nem real. Ela não consiste nem no ensino uniforme de crianças da república nem na disponibilidade dos produtos de baixo preço nas estantes de supermercados. A igualdade é fundamental e ausente, ela é atual e intempestiva, sempre dependendo da iniciativa de indivíduos e grupos que, contra o curso natural das coisas, assumem o risco de verificá-la, de inventar as formas, individuais ou coletivas, de sua verificação. (idem, p. 13-14) 
É na afirmação não apenas da impossibilidade, mas mesmo da inutilidade, de comprovar essa igualdade que o princípio pedagógico materializa-se:

E jamais poderemos afirmar: todas as inteligências são iguais. Isso é inegável. Nosso problema, contudo, não é provar que todas as inteligências são iguais. É ver o que se pode fazer a partir dessa suposição. E, para isso, basta-nos que essa opinião seja possível, isto é, que nenhuma verdade contrária seja demonstrada. (idem, p. 56)

A igualdade das inteligências é assumida como pressuposto a ser verificado e actualizado pelas práticas relacionais, e não como objectivo da transformação que deve ser operada nos sujeitos. Rancière identifica a possibilidade da desigualdade das vontades, e não da desigualdade das inteligências: a haver objectivo, então ele será de potenciar a vontade de cada um, que assim poderá fazer uso e actualizar sua inteligência. Associada à conviç̧ão da igualdade das inteligências está a capacidade única e comum a todos os seres humanos: ser capazes de autoinstruir-se, de ensinar-se. O acto de ensinar-se parece inspirado em Rousseau, no entanto, Rancière nega essa associação, considerando que os alunos de Jacotot aprenderam sem um determinado tipo de mestre, mas não sem mestre. Ao contrário da proposta de Rousseau, Jacotot imiscui os sujeitos da educação no mundo real, na sociedade tal como ela existe e funciona, não há a demanda por lugares supostamente puros que mantenham a pureza dos neófitos; é aqui que se encontrará a coisa comum que permite a relação entre professores e alunos. Isso porque o que Jacotot terá conseguido foi dissociar mestre de sábio - o professor pode ignorar as matérias que faz aprender, é o "mestre ignorante" que dá título ao livro.

Essa proposta assenta em uma definição extraordinariamente aberta de ser humano como "uma vontade servida por uma inteligência" (idem, p. 61). É nessas deambulações que se desencadeia uma nova práxis educativa: verificar, de modos diversos, a igualdade das inteligências acicatando o poder da vontade e forçando o uso da inteligência. Isso é feito por meio da negação da explicação.

Explicar alguma coisa a alguém é, antes de mais nada, demonstrar-lhe que não pode compreendê-la por si só. Antes de ser o ato do pedagogo, a explicação é o mito da pedagogia, a parábola de um mundo dividido em espíritos sábios e espíritos ignorantes, espíritos maduros e imaturos, capazes e incapazes, inteligentes e bobos. O procedimento próprio do explicador consiste nesse duplo gesto inaugural: por um lado, ele decreta o começo absoluto - somente agora tem início o ato de aprender; por outro lado, ele cobre todas as coisas a serem aprendidas desse véu de ignorância que ele próprio se encarrega de retirar. Até ele, o pequeno homem tateou às cegas, num esforço de adivinhação. Agora, ele vai aprender. (idem, p. 20)

Aparentemente, o contraponto do professor que não explica é o aluno que não compreende. Contudo, o que se nega é o acto mimético de compreensão: compreender como o explicador compreende e de compreender como forma de saciar o 
intelecto perante as questões e os temas que se lhe vão colocando. De acordo com os autores, é no repousar das inteligências que a desigualdade emerge, porque aí sim as reacções são diferentes e é aí que a relação educadora se pode tornar central: em não deixar repousar e em obrigar os alunos a usar, melhor, a actualizar sua inteligência - e a não preguiçar.

Portanto, se não explica, o professor que encontra a coisa comum e confia na igualdade das inteligências precisa verificar a existência de vontade de aprender. De facto, os alunos de Jacotot tinham essa condição, uma vez que escolheram aprender francês, acolheram a coisa comum, lendo o livro bilíngue. Para chegarem ao francês, fizeram-no como puderam, pelo sentido dos parágrafos e das frases, e não logicamente e sequencialmente pela palavra, pelas regras gramaticais ou pela explicação dos modos de as usar. Procederam para com uma língua estrangeira como as crianças pequenas fazem com a língua materna, usaram da adivinhação e da intuição e fruíram do acaso - elementos recusados por qualquer modelo pedagógico, desde os tradicionais aos progressistas. É pelo acaso universal de viver uma vida em que os outros estão igualmente presentes que nos defrontamos com a obrigatoriedade de ser e aprender e usar códigos válidos. A capacidade que subjaz à aprendizagem da língua materna - uma aprendizagem sem compreensão explícita de seus mecanismos linguísticos, fonéticos ou gramaticais - é inibida e inviabilizada pela escolarização. A escola inibe a capacidade de aprender pelo facto de almejada a compreensão ordenada, progressiva e disciplinada dos saberes: uma compreensão que requer a explicação e só dela pode advir.

Ao reconhecer que os outros (no caso, os alunos) são igualmente capazes, inteligentes, ignorantes e cheios de vontade de aprender como ele próprio, o mestre emancipa-os pela força, obrigando-os a usar a inteligência. Se o (a)caso do livro bilíngue for tomado como símbolo, percebe-se que o que o mestre ignora não é apenas o neerlandês, mas é antes o que e como seus alunos aprenderão francês, como se relacionarão com essa nova aprendizagem, que relevância terá para cada um deles, como influenciará a composição do grupo e suas aprendizagens futuras, entre tantas outras coisas. O mestre não poderá mais ser um sábio, a proposta é que seja um mestre ignorante e emancipador que obriga seus alunos a usarem sua própria inteligência.

\section{EXPERIÊNCIA PASSIVA}

No centro da teorização da educação de Larrosa $(2000,2001,2002)$ está a experiência humana assim entendida e marcada pelos trabalhos de Lyotard (1989) e de Arendt (2001) já referidos.

A experiência, a possibilidade de que algo nos aconteça ou nos toque, requer um gesto de interrupção, um gesto que é quase impossível nos tempos que correm: requer parar para pensar, parar para olhar, parar para escutar, pensar mais devagar, olhar mais devagar, e escutar mais devagar; parar para sentir, sentir mais devagar, demorar-se nos detalhes, suspender a opinião, suspender o juízo, suspender a vontade, suspender o automatismo da acção, cultivar a atenção e a delicadeza, abrir os olhos e os ouvidos, falar sobre o que nos acontece, aprender 
a lentidão, escutar aos outros, cultivar a arte do encontro, calar muito, ter paciência e dar-se tempo e espaço. (Larrosa, 2002, p. 24)

Essa poética da experiência é ponto de partida para uma abordagem extraordinariamente inspirada e inspiradora: pensar a educação fora da moda, fora do sistema vigente, para além do tempo e dedicada à amplitude da existência humana. $\mathrm{O}$ autor propõe que a educação seja entendida como uma "experiência dotada de sentido" (idem, p. 21) que ocorre para além e aquém da racionalidade técnica que lhe foi imposta ao longo do século XX, sempre orientada para fins previamente definidos. É nesse sentido que Larrosa (2001, p. 285) designa a descontinuidade como figura da educação que responde à conceptualização da criança como alteridade:

Gostaria, portanto, de esboçar uma ideia da educação como figura da descontinuidade: pensar a transmissão educativa não como uma prática que garanta a conservação do passado ou a fabricação do futuro mas como um acontecimento que produz o intervalo, a diferença, a descontinuidade, a abertura do porvir. [...] Entendo também por descontinuidade uma forma de temporalidade que nada tem a ver com a ideia de processo, ou com as ideias subordinadas de desenvolvimento ou de progresso, com todas essas ideias que pressupõem um tempo contínuo, dotado de direcção e de sentido, cronologicamente orientado. Com a palavra descontinuidade, portanto, pretendo nomear um pensamento da educação que perturbe o esquema dessa totalização temporal de corte humanista, ainda sob o modelo da Bildung, que subjaz às formas dominantes demasiado seguras e asseguradas da história e às figuras demasiado tradicionalistas da tradição.

Para sustentar a educação como descontinuidade, o autor convoca um conjunto de ideias que têm vindo a ser abandonadas no contexto de correntes e convenções sobre as formas mais adequadas e consensuais de pensar a educação:

- em vez da atenção exclusiva na aquisição e na aprendizagem, o autor recupera a transmissão educativa;

- para além da actividade como marca da educação moderna das crianças, propõe um novo olhar sobre a passividade;

- para além da demanda insistente para a autonomia, reabilita também a heteronomia;

- longe da demanda por competências predeterminadas, o autor afirma os sentidos do conbecimento e do saber.

A própria recuperação dessas ideias provoca também uma descontinuidade no pensamento sobre a educação contemporânea; são vários os autores que, de diferentes perspectivas, contribuem para a quebra do vínculo entre educação e progresso linear e contínuo (Ambrósio, 2001; Biesta, 2010a; Edwards, 2009; Gewirtz, 2008; Gonçalves, 2010; Masschelein; Simons, 2013). Larrosa valoriza a experiência 
como capacidade humana essencial de nos sentirmos abandonados às coisas que nos tocam - e dá como exemplos comuns os momentos de esquecimento de si provocados por ler um livro ou ver um filme.

A experiência assim percebida distingue-se das experiências ativas propostas pela educação progressista e pela mais recente aprendizagem ao longo da vida, especialmente por apelar à recetividade e a certa passividade no sentido do momentâneo esquecimento de si perante o mundo; também por ser subjetiva e intersubjetiva; por promover a alteridade e a heteronomia, e não apenas autonomia e a individualidade, por não ter utilidade extrínseca. Colocar a experiência no centro da educação exige alguma exposição do sujeito aos acontecimentos, aceitando riscos e imprevistos, nos acontecimentos educativos como em seus resultados eventuais.

Outra dimensão da experiência é o modo como ela é promotora de construção pessoal de um saber específico, sendo mais transformadora que reprodutora. Dessa conceptualização indicia-se uma proposta epistemológica para um entendimento de conhecimento que não trata da verdade, mas do sentido e do sem sentido do que nos acontece. O saber assim é finito, ligado à existência de cada indivíduo, contingente e relacional: "o saber da experiência se dá na relação entre conhecimento e vida humana" (Larrosa, 2002, p. 26). Como tal, os sentidos atribuídos à experiência e ao saber afastam-se das propostas modernas, por não serem estáveis, objetivos e repetíveis, sendo antes dialógicos e generativos - geradores de saberes antecipadamente insuspeitos e imprevistos.

$\mathrm{O}$ acontecimento é comum, mas a experiência é para cada qual sua, singular e de alguma maneira impossível de ser repetida. O saber da experiência é um saber que não pode separar-se do indivíduo concreto em quem encarna. Não está, como o conhecimento científico, fora de nós, mas somente tem sentido no modo como configura uma personalidade, um caráter, uma sensibilidade ou, em definitivo, uma forma humana singular de estar no mundo, que é por sua vez uma ética (um modo de conduzir-se) e uma estética (um estilo). (idem, p. 27)

Assim percebidas, as próprias situações educativas poderão ser descontínuas, no sentido de que poderão proporcionar a ocorrência ocasional e nunca garantida de acontecimentos que se podem revelar experiências para alguns dos sujeitos presentes e capazes de se expor (e não apenas de por ou impor...) às situações. Nesse sentido, a pedagogia reside em uma certa convicção de que a vida real e a construção de sentidos sobre esta deverão ser elementos centrais da educação, que, em vez de se encaixar nos processos educativos planeados e pré-determinados, os perturbam e interrompem. Decorre então a evidência de que todos os sujeitos implicados terão de se expor aos acontecimentos educativos:

Também a experiência, e não a verdade, é o que dá sentido à educação. Educamos para transformar o que sabemos, não para transmitir o já sabido. Se alguma coisa nos anima a educar é a possibilidade de esse acto de educação, essa experiência, esse gesto nos permita liberar-nos de certas verdades, de modo 
a deixarmos de ser o que somos, para ser outra coisa para além do que vimos sendo. (Larrosa; Kohan, 2002, s.p.)

Essa concepção de experiência e de educação afirma uma possibilidade de relação educadora em que a diferença de papéis entre os sujeitos não reside na acepção redutora de que apenas um polo da relação aprende, cresce, modifica-se, e o outro se mantém tal como estava antes da situação de educação desencadeada, por ser estável, feito, acabado de algum modo. Se o acontecimento é possível e dotado de sentido e o conhecimento é contingente e relacional, as partes que estão em relação reconfigurar-se-ão (educador, educando, conhecimento, relação, espaço, sentido...).

Consistentes com as deambulações de Larrosa são as palavras de Skliar (2003), anteriormente citadas, sobre o difícil e dificultado lugar da vida, da experiência da existência humana dentro dos espaços destinados à educação, dentro dos serviços para crianças por excelência que são as escolas. Noutros trabalhos ensaiei uma análise das visitas escolares como possibilidades para a exposição e o abandono a acontecimentos imprevistos e necessitados de construção de sentido - porque assim se descontinua a tendência de enclausurar a educação dentro da escola e de a situar apenas ao longo do programa (Gomes, 2012).

\section{PEDAGOGIA DA INTERRUPÇÃO}

Os trabalhos de Gert Biesta (2006, 2010a) aprofundam o tema da responsabilidade dos sujeitos implicados em educação. O pensamento educativo desse autor assenta em premissas decorrentes de seu enquadramento pós-humanista, pragmático e ético. Nesse sentido, enfatiza a necessidade contemporânea de questionar explicitamente o que se considera ser uma boa educação, considerando que actualmente esse debate foi substituído pelo debate sobre o que funciona em educação, como se pode medir a eficácia ou qual a utilidade dos processos educativos. Biesta (2006,2010a) considera que os propósitos da educação têm estado organizados em torno de três eixos fundamentais: a qualificação, a socialização e a subjectificação. Com qualificação o autor remete para aspectos do desenvolvimento e da aprendizagem de conhecimentos, competências e saberes-fazer que surgem como conteúdos mais explícitos dos processos de escolarização e formação; já com socialização, refere-se aos mecanismos de aprendizagem e conformação às regras sociais preexistentes, assim como aos elementos de construção de identidade cultural e de integração na comunidade; por fim, a subjectificação remete para a necessidade de, por meio dos processos educativos, os sujeitos individuais terem espaço e condições para se construírem enquanto seres únicos na relação que estabelecem com os outros e com o mundo comum. É por explicitar a singularidade em cada ser humano e a novidade que cada um pode trazer à comunidade que a proposta-síntese da pedagogia da interrupção enquadra-se no aprofundamento dos contributos da teoria da educação para a percepção da alteridade dos sujeitos da educação, nomeadamente das crianças.

A pedagogia da interrup̧̧ão que promove a educação como circunstância em que as relações e reacções humanas sejam possíveis e não obscurecidas pela urgência em normalizar e em quantificar resultados de escolarização. Nesse sentido, a 
pedagogia da interrupção começa por interromper a própria ideia-base de que a educação tem como função primordial a formação dos indivíduos:

Uma pedagogia da interrupção não é uma pedagogia "forte"; não é uma pedagogia que pode, em qualquer sentido, garantir seus "resultados". É antes uma pedagogia que reconhece a fraqueza fundamental da educação perante a questão da subjetificação. Esta fraqueza ontológica da educação é, ao mesmo tempo, a sua força existencial, porque é só quando se desiste da ideia de que a subjetividade humana pode de alguma forma ser educacionalmente produzida que se abre espaço para a singularidade vir ao mundo. Isto é o que está em jogo em uma pedagogia de interrupção. (Biesta, 2010a, p. 91, tradução minha)

A pedagogia da interrupção surge, assim, como uma consequência e uma síntese das propostas apresentadas por Biesta (2006, 2010a) perante o desafio que o pensamento pós-humanista coloca à educação: como pensar a educação se a resposta ao que é ser humano decorrer, em vez de anteceder, dos acontecimentos e processos educativos? Segundo o autor, suas propostas organizam-se em torno de dois conceitos-chave: singularidade e tornar-se presente t $^{7}$ no mundo comum; da leitura e interpretação que faço da obra de Biesta, considero existir um terceiro conceito-chave: responsabilidade educativa. ${ }^{8}$

A singularidade é o conceito que mais directamente decorre do posicionamento pós-humanista, uma vez que, em detrimento da visão essencialista sobre o que é ser humano, acentua a convicção existencial de que cada ser transporta a possibilidade de ser e fazer o que nunca antes tinha sido feito e que nunca depois se repetirá. $\mathrm{O}$ conceito de singularidade é ainda considerado não uma característica de cada um, mas antes um acontecimento da vida relacional. Acrescentando ao entendimento mais simples de singularidade como diferença perante o outro, Biesta (2010a, p. 90, tradução minha) clarifica:

[singularidade] não como algo que tem a ver com o nosso ser, mas como algo que tem a ver com a nossa existência [...] não pode ser produzida; não é algo que possa ser o resultado garantido de uma intervenção educacional particular ou pedagogia particular. Mas, apesar de a singularidade não poder ser produzida, é bastante fácil de se certificar de que a singularidade não vai aparecer, não terá qualquer hipótese de aparecer. Isso acontece quando impedimos os nossos alunos de qualquer encontro com a alteridade e diferença, qualquer encontro que poderia interromper as suas formas normais de ser e poderia provocar uma

6 Tradução minha de "uniqueness".

7 Tradução da expressão "comming into presence", que devo à minha colega e amiga Carla Augusto.

8 Embora esse conceito possa estar subjacente aos anteriores, o facto é que tem uma forte especificidade, sendo grande o seu contributo para recolocar a questão da responsabilidade em educação. 
resposta ágil e responsável. Isto é, quando deixamos que os nossos alunos se tornem imunes ao que os possa afetar, interromper ou perturbar.

Assumindo a singularidade desse modo, então a "responsabilidade educativa" emerge quando o educador impede que educação torne-se imunização, como já nos anos 1990 escrevia Paulo Freire (1996). É uma responsabilidade dos educadores e decorre da assumpção dos riscos contidos na relação educadora e das exigências que esta transporta. Isso afecta enormemente o lugar e o papel do professor, que terá de pautar sua acção educativa por critérios intersubjectivos que exigem o tempo, a calma, a escuta, e ao qual se acrescenta a responsabilidade pelo todo: pelas questões colocadas, pela oportunidade e pela capacidade de obrigar os alunos a dar respostas, ou seja, a posicionar-se efectivamente e a expor-se no mundo comum.

Biesta (2006) considera que as características particulares dessa relação são: a confiança cega (uma vez que nem o desenrolar da relação nem seus resultados poderão ser à partida conhecidos) e a responsabilidade na incerteza, que decorre do facto de a relação educadora apelar e reconfigurar as subjectividades em relação, e assim a responsabilidade dos professores pelos estudantes não se baseia no conhecimento daquilo por que se estão a responsabilizar. $\mathrm{O}$ carácter distintivo da relação educacional assenta em um terceiro vector particularmente estimulante e que evidencia a interdependência dos três elementos: a violência transcendental conceito de Derrida que Biesta considera particularmente válido para pensar a relação educadora e que se refere à violência que está para além do conhecimento possível no momento em que ela é assumida. "É violento na medida em que não deixa os indivíduos sossegados, na medida em que faz perguntas difíceis e cria situações difíceis. Mas é precisamente através deste exercício que se tornar presente deve ser possível” (Biesta, 2005, p. 62-63, tradução minha). A transcendência aqui se refere ao trabalho dos professores e educadores, no sentido de que todas essas características da relação educacional têm condições de possibilidade muito delicadas que apenas o professor pode assegurar e que se devem nortear pela vontade de não impedir a singularidade dos sujeitos em presença. $\mathrm{O}$ autor não explicita quais são essas condições, considerando que a pedagogia da interrupção não oferece técnicas, mas antes defende uma abordagem.

É afirmada a relevância de o trabalho dos professores ser pensado não apenas no sentido de "dar" (a matéria, dar a ver, dar a oportunidade), mas como o de "pedir" respostas singulares a questões difíceis que obrigam os alunos a posicionar-se e a expor-se. Como contraponto, Biesta refere-se a "learning as responding", que enfatiza seu carácter relacional e contextual como alternativa a um entendimento da aprendizagem como acumulação de conhecimentos. $\mathrm{O}$ uso da expressão inglesa "responding" apela a uma densificação do acto comunicacional das situações educativas; "responding" não é exactamente responder, que seria "answering", é responder responsavelmente e correspondendo a um desafio aceite, é responder como um acto de assumpção de si na resposta dada - aprender como (co)responder refere-se a mostrar quem cada um é e onde cada um se situa, é um modo de tornar-se presente [...] e tornar-se presente é exaustivamente relacional e intersubjetivo" (idem, p. 62). 
Assim se articula o conceito de "tornar-se presente" com a responsabilidade educativa necessária para que tal acontecimento ocorra em espaços e tempos de educação. Em obras posteriores (Biesta, 2010a), o conceito é aprofundado com as influências de Arendt sobre a esfera pública como uma das condições da humanidade, assumindo que se refere a "tornar-se presente no mundo":

Considerando que a noção de "entrar em presença" enfatiza muito o que acontece no lado do indivíduo, talvez seja melhor pensar sempre o entrar em presença como um processo de tornar-se presente no mundo - onde mundo representa um mundo de pluralidade e diferença. (idem, p. 85, tradução minha)

O aprofundamento do conceito para "tornar-se presente no mundo" acrescenta à responsabilidade educativa a possibilidade de evidenciar o mundo da pluralidade e da diferença que deve constituir o lugar educativo por excelência. Acentuam ainda a necessidade e possibilidade de integrar o pensamento sobre a dimensão pública da educação em detrimento de sua leitura privada, convergindo em uma perspectiva mais pedagógica e existencial. Destaca-se a referência comum em Biesta (idem) e em Larrosa (2002) às ideias de Arendt sobre e novidade contida em, e possibilitada por, cada novo ser humano que nasce (um princípio) e da chegada de cada ser humano a um contexto até então desconhecido (um principiante). É essa novidade que justifica a educação e a responsabilidade educativa de permitir que cada ser se cumpra como princípio e principiante no mundo comum, pois "não é só no momento do nascimento que algo de novo surge no mundo; nós trazemos continuamente novos princípios ao mundo, através das nossas palavras e das nossas acções"(Biesta, 2010a, p. 82).

\section{CONCLUSÃO}

A compreensão da educação como acontecimento ou evento complexo, a ênfase em seu carácter relacional, bem como em seu lugar central para a emergência da singularidade constituída pelos sujeitos implicados, são elementos presentes nas propostas teóricas aqui reunidas. Estas defendem a negação da racionalidade técnica pelo uso recorrente das ideias de interrupção, perturbação ou descontinuidade como características necessárias das situações de educação, e não como problemas a evitar. Tomando posição sobre a educação como modo de fazer mundo comum, as propostas teóricas que aqui dei a ler divergem em aspectos importantes: o lugar atribuído à igualdade e à singularidade; a possibilidade de a escola como instituiçáo social ser também um lugar de igualdade; a questão da responsabilidade educativa.

A igualdade a que Rancière e Jacotot apelam surge como um princípio da relação entre as pessoas, e não como um objectivo da acção (educativa). A igualdade não corresponde a uma anulação das diferenças e das singularidades, mas antes a uma racionalidade que conduz o agir com base na crença de que os outros são igualmente

9 Tradução minha da expressão "coming into the world". 
capazes de agir (racionalmente). Também é nesse sentido que, embora não usando o conceito de igualdade, Biesta expõe a violência do agir educativo. Para ele, o agir educativo obriga as pessoas implicadas a exprimir-se, e essa violência radica na convicção da igualdade das inteligências daqueles que comunicam, no sentido de que põem coisas em comum, e ao fazê-lo exigem dos outros essa mesma capacidade - e não esse mesmo pensamento. Uma radical divergência emerge dessa argumentação: Gert Biesta acredita na possibilidade da escola como lugar para o agir educativo, ao passo que Rancière e Jacotot menosprezam a possibilidade de uma instituição formal do sistema social poder cumprir desígnios que defende serem exclusivos da relação entre (homens) iguais. Relativamente a esse diferendo, o texto de Larrosa recupera os mecanismos da escola e de sua condição de separação e de afastamento da vida do sistema social que a sustenta. É aqui que encontra a possibilidade do agir educativo no interior de instituições sociais: recuperando certa ancestralidade da educação e recusando a colocar-se ao serviço de programas sociais, mas antes ao serviço da vontade de saber, da vontade de comunicar e da vontade de pertencer, fazer e usar mundo comum.

O mundo comum, para ser comum, exige que as pessoas o usem livremente, e não com objectivos pré-determinados. $\mathrm{O}$ mundo, para ser comum, precisa ser comunicado. É disso que trata a educação, e é por isso que a escola como instituição tem sempre de ser conservadora e não pode abraçar o utilitarismo social: porque é preciso tempo e espaço para comunicar, para se fazer entender e para assim fazer um mundo comum. É por se filiar nessa abordagem fundada na obra de Arendt que Biesta distancia-se do mestre ignorante: é por não poder ignorar o que os estudantes farão com suas aprendizagens que o professor encontra a violência da responsabilidade educativa. É por uma forte assumpção da igualdade das inteligências que Larrosa e Rancière não consideram a necessidade da responsabilidade educativa como a que se estende ao outro - mas antes a que reside em si.

Em contrapartida, as estratégias que configuram o back to basics que foram comentadas servem propósitos de controlo e normalização do trabalho dos professores, em uma tentativa de asfixia das dimensões humanas e pedagógicas do trabalho docente. $\mathrm{O}$ que se designa de regresso ao básico, como se de um regresso a saberes fundamentais, canónicos e indiscutíveis se tratasse, é, acima de tudo, um reforço da submissão da infância e de tudo o que há de infantil na relação pedagógica.

Contudo, escrevo este artigo imbuída da esperança de que é possível reagir às crises evitando refúgios anacrónicos e falaciosos. É possível repensar a pedagogia para além de automatismos autoritários e dogmáticos que colocam cada um ao serviço de funções e projetos que o superam. É possível reafirmar a necessidade de resistir ao regime que tem sustentado o funcionamento da educação e assumir suas falhas, constituindo-as como brechas para um agir pedagógico mais humilde e mais expectante, configurando uma pedagogia mais passiva que impositiva, mais existencial que lucrativa. Um modo de aceitar nossa humanidade no agir educativo é assumir a possibilidade da pedagogia alicerçada na dúvida e na busca incessante, fundada na rejeição do funcionarismo eficaz perante objetivos embrutecedores. Educar assim nos habilita a integrar uma comunidade de pensamento e aç̧ão - que pode até ser uma 
comunidade composta pelos que não têm nada em comum - que se atreve a ressignificar de modos vibrantes e generativos os acontecimentos educativos.

\section{REFERÊNCIAS}

Амв rósio, T. Educação e desenvolvimento. Contributo para uma mudança reflexiva da educação. Monte da Caparica: FCT-UNL; UIED, 2001.

Arendt, H. A crise na educação. In — Quatro textos excêntricos. Tradução de Olga Pombo. Lisboa: Relógio D’Água, 2000. p. 21-53.

A condição bumana. 1. ed. 1958. Lisboa: Relógio D’Água, 2001.

Beillerot, J. A sociedade pedagógica. Lisboa: Rés Editora, 1985.

Bernstein, B. Das pedagogias aos conhecimentos. Educação, Sociedade e Culturas, Porto: Afrontamento, n. 15, p. 9-17, 2001.

Biesta, G.J.J . Against learning. Reclaiming a language for education in a time of learning. Nordisk Pedagogik, Oslo: Universitetsforlaget, p. 54-66, 2005.

Beyond learning. Democratic education for a human future. Boulder, London: Paradigm Publishers, 2006.

. Good education in an age of measurement: ethics, politics, democracy. Colorado: Paradigm, 2010a.

. On the weakness of education. In: Kerdeman, D. et al. Philosophy of education 2009. Urbana-Champaign, IL: Philosophy of Education Society, 2010b. p. 354-362.

Chão. Henri Lefebvre. O direito à cidade. JA Jornal Arquitectos, Lisboa: Ordem dos Arquitectos, 228, p. 65-80, jul./set. 2007.

Edwards, R. Introduction: life as a learning context? In: Edwards, R.; Biesta, G.J.J., THORPE, M. Rethinking contexts for learning and teaching. Oxon, New York: Routledge, 2009. p. 1-13.

Fendler, L. Lurking, distilling, exceeding, vibrating. Studies in Philosohy and Education, Dordrecht: Springer, n. 31, p. 315-326, 2012.

Fernandes, M. R. Mudança e inovação na pós-modernidade. Perspectivas curriculares. Porto: Porto Editora, 2000.

Freire, P. Pedagogia da autonomia. São Paulo, 1996. Disponível em: <www.paulofreire. ufpb.br >. Acesso em: 12 set. 2011.

Gewirtz, S. Give us a break! A sceptical review of contemporary discourses of lifelong learning. European Educational Research Journal, Oxford: Symposium Journals, n. 7(4), p. 414-424, 2008.

Gomes, E. X. The (un)bearable educational lightness of common practices. On the use of urban spaces by schoolchildren. Studies in Philosophy and Education, Dordrecht: Springer, v. 31, n. 3, p. 289-302, 2012.

Gonçalves, T. N. R. Promoção de habilidades cognitivas e educação: um modelo de análise de programas de desenvolvimento cognitivo. Revista Brasileira de Educação, 
Rio de Janeiro: ANPEd; Campinas: Autores Associados, v. 15, n. 45, p. 564-598, 2010.

Koнan, W. O. Infância. Entre educação e filosofia. Belo Horizonte: Autêntica, 2003. Larrosa, J. L. Pedagogía profana. Estudios sobre lenguaje, subjetividade, formación. Buenos Aires: Ediciones Novedades Educativas, 2000.

Dar a palavra. Notas para uma dialógica da transmissão. In: LARrosa, J.; SKLIAR, C. (Orgs.). Habitantes de Babel. Politicas e poéticas da diferença. Belo Horizonte: Autêntica, 2001. p. 281-295.

. Notas sobre a experiência e o saber de experiência. Revista Brasileira de Educação, Rio de Janeiro: ANPEd; Campinas: Autores Associados, n. 12, p. 20-28, 2002. Disponível em: <http://www.anped.org.br/rbe/rbedigital/RBDE19/RBDE19_04_ JORGE_LARROSA_BONDIA.pdf >. Acesso em: 3 out. 2010.

.; Kohan, W. Apresentação de $O$ mestre ignorante de Jacques Ranciere. Scribd, 2002. Disponível em: <http://www.scribd.com/doc/21268185/O-mestre-ignorante-Jacques-Ranciere >. Acesso em: 11 jan. 2010.

Levinas, E. O mesmo e o outro. In: Totalidade e infinito. Lisboa: Edições 70, 1988, p. 19-39.

Lyotard, J.-F. Prefácio: do humano. In: O inumano. Considerações sobre o tempo. Lisboa: Estampa, 1989, p. 9-15.

Masschelein, J. E-ducando o olhar: a necessidade de uma pedagogia pobre. Educação $\Xi$ Realidade, Porto Alegre: Faculdade de Educação da Universidade Federal do Rio Grande do Sul, v. 33, n. 1, p. 35-48, 2008.

.; Simons, M. In defence of the school. A public issue. Leuven: E-ducation, Culture \& Society Publishers, 2013.

NóvoA, A. Evidentemente. Histórias de Educação. Porto: Asa, 2005.

Ó, J. R. O governo de si mesmo. Modernidade pedagógica e encenações disciplinares do aluno liceal. Lisboa: Educa, 2003.

Pina, M. A. Uma história que começa pelo fim. In: Histórias que me contaste tu. Lisboa: Assírio e Alvim, 2002. p. 18-25.

RANCIÈre, J. O mestre ignorante. Cinco lições sobre a emancipação intelectual. Belo Horizonte: Autêntica, 2002.

Schérer, R. Infantis: Charles Fourier e a infância para além das crianças. Belo Horizonte: Autêntica, 2009.

.; GiL, J.; Brito, V. Devir criança: devir maior ou devir menor. Conversa com René Schérer. Imprópria, Lisboa: UNIPOP; Tinta da China, n. 2, p. 65-77, 2012.

SkLiar, C. Jacotot-Rancière ou a dissonância inaudita de um pedagogia (felizmente) pessimista. Educação E̋ Sociedade, Campinas: CEDES, v. 24, n. 82, p. 29-240, 2003. Disponível em: <http://www.scielo.br/pdf/es/v24n82/a13v24n82.pdf>. Acesso em: 20 jan. 2011. 
Smeyers, P.; Wringe, C. Adults and children. In: Blake, N.; Smeyers, P; Smith, R.; Standish, P. The blackwell guide to the philosophy of education. Malden; Oxford; Melbourne; Berlin: Blackwell Publishers, 2003. p. 311-325.

VIRno, P. Infância e pensamento crítico. Imprópria, Lisboa: Unipop; Tinta da China, n. 2, p. 34-44, 2012.

\section{SOBRE A AUTORA}

Elisabete Xavier Gomes é doutora em ciências da educação pela Universidade Nova de Lisboa (Portugal). Professora da Escola Superior de Educadores de Infância Maria Ulrich (Portugal).

E-mail:emxvg@campus.fct.unl.pt

Recebido em fevereiro de 2013 Aprovado em julho de 2014 